Proceedings

\title{
Photocross-Linked Bio-Based Polymers for Potential Application in Optical 3D Printing ${ }^{\dagger}$
}

\author{
Migle Lebedevaite and Jolita Ostrauskaite * \\ Department of Polymer Chemistry and Technology, Kaunas University of Technology; \\ migle.lebedevaite@ktu.lt \\ * Correspondence: jolita.ostrauskaite@ktu.lt; Tel.: +370-61028625 \\ + Presented at the First International Conference on “Green” Polymer Materials 2020, 5-25 November 2020; \\ Available online: https://cgpm2020.sciforum.net/. \\ Published: 4 November
}

\begin{abstract}
Acrylated epoxidized soybean oil (AESO)-based resins were developed as a biobased resin for potentials application in optical 3D printing. AESO was photocross-linked with myrcene (MYR) and vanillin dimethacrylate (VDM) or divinylbenzene (DVB, for comparison) in the presence of 2,2-dimethoxy-2-phenylacetophenone (DMPA) as photoinitiator. The higher amount of myrcene in the compositions resulted better homogenization and lower viscosity, though prolonged photocross-linking reaction and reduced mechanical and thermal properties of the synthesized polymers. The used aromatic compounds (VDM or DVB) improved mechanical and thermal properties of cross-linked polymers. Replacing DVB with VDM in the systems led to the higher photocross-linking rate and higher yield of insoluble fraction. The resin composed of only plantderived monomers AESO/MYR/VDM, molar ratio 1:1:3, was indicated as a suitable renewable photoresin for potential application in optical 3D printing.
\end{abstract}

Keywords: biopolymers; renewable polymers; cross-linking; photopolymerization; thermosets

\section{Introduction}

In recent years, additive manufacturing or 3D printing gained a lot of interest as a highly accurate, fast, and low raw material using technology [1]. Optical 3D printing is a photopolymerization method employing UV/VIS light to polymerize photosensitive resin layer by layer. Synthetic acrylates are the most frequent choice in optical 3D printing due to their relatively low cost and high light sensitivity [2].

As a replacement of petroleum-derived monomers, renewable raw materials such as natural oils are one of the most promising starting materials for polymer synthesis. Acrylated epoxidized soybean oil (AESO) could be easily cross-linked by UV/VIS light using an appropriate photoinitiator [3]. Though, due to poor mechanical properties of AESO polymers predetermined by fatty acid long aliphatic chains, various petroleum-derived aromatic comonomers such as styrene, divinylbenzene (DVB), dicyclopentadiene acrylonitrile and others are added [4,5]. Vanillin dimethacrylate (VDM) or methacrylated vanillin alcohol, which can be produced from lignin, is a considerable candidate to replace petroleum-derived aromatic compounds due to its high reactivity [6].

Synthetic reactive diluents are often used to reduce the high viscosity $(19000-31000 \mathrm{cP} / \mathrm{mPa} \cdot \mathrm{s})$ of AESO [7] and to improve properties of cross-linked polymer. Natural compound myrcene (MYR), a component of the essential oils of several plants, including bay, mango and others [8], could replace the petroleum-derived reactive diluents due to the very low viscosity [9] and the presence of three reactive double bonds, one of which is conjugated.

In this study, the resins composed of commercially available AESO, DVB, and MYR were photocross-linked in various ratios. Plant-derived VDM was used as a replacement of DVB (Figure 
1). The investigation of photocross-linking kinetics of the designed resins was carried out by realtime photorheometry for the first time. The dependency of photocross-linking rate and properties of the cross-linked polymers on the resin composition was determined. The resin composed of only plant-derived monomers, AESO, MYR, and VDM, showed characteristics suitable for potential application in optical 3D printing.

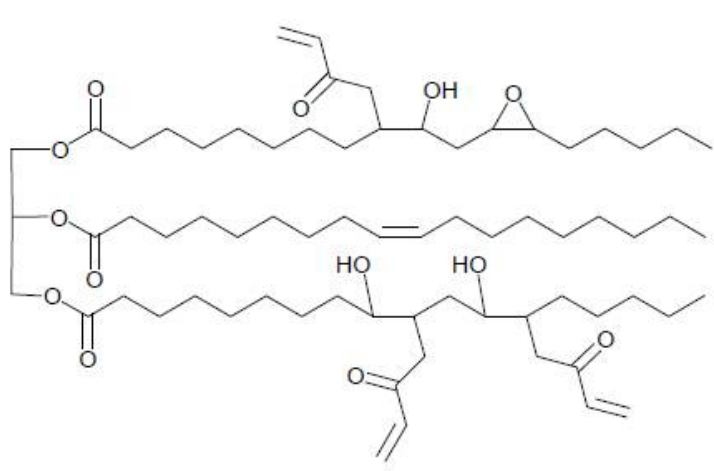

AESO

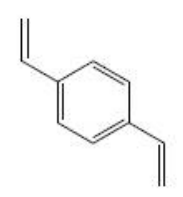

DVB<smiles>C=CC(=C)CCC=C(C)C</smiles>

MYR

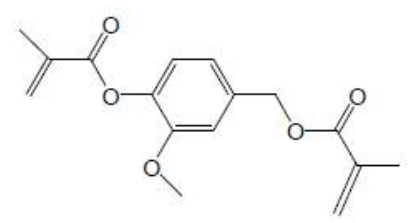

VDM

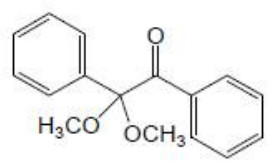

DMPA

Figure 1. Chemical structure of acrylated epoxidized soybean oil (AESO), myrcene (MYR), divinylbenzene (DVB), vanillin dimethacrylate (VDM) and 2,2-dimethoxy-2-phenylacetophenone (DMPA).

\section{Materials and Methods}

\subsection{Materials}

Acrylated epoxidized soybean oil (AESO, an average number of acryloyl groups per molecule calculated from 1H-NMR spectrum is 2.7 and 0.3 of epoxide groups), myrcene or 7-methyl-3methylene-1,6-actadiene (MYR), divinylbenzene (DVB), and 2,2-dimethoxy-2-phenylacetophenone (DMPA) were purchased from Sigma-Aldrich. Chloroform was purchased from Chempur. Vanillin dimethacrylate was purchased from Specific Polymers. All materials were used without further purification.

\subsection{Preparation of Cross-Linked Polymers}

Curing formulations were prepared by mixing adequate amounts (Table 1) of AESO, MYR, and aromatic compound (DVB or VDM) at $40{ }^{\circ} \mathrm{C}$ with magnetic stirrer. 3 mol. $\%$ of photoinitiator DMPA was added. Prepared resins were poured into a tablet-shaped $(Q 15 \mathrm{~mm}, \mathrm{~h} 3 \mathrm{~mm})$ Teflon mold and irradiated with Helios Italquartz, model GR.E $500 \mathrm{~W}$ lamp which intensity was $310 \mathrm{~mW} \cdot \mathrm{cm}^{-2}$ at the distance of $15 \mathrm{~cm}$ until hard polymer tablets were formed.

\subsection{Soxhlet Extraction}

The yield of insoluble polymer fraction (YIF) was determined by Soxhlet extraction. Samples of prepared polymers were wrapped into a filter package and put into a Soxhlet apparatus. Extraction was performed with chloroform for $24 \mathrm{~h}$. Extracted polymer specimens were dried under vacuum to constant weight. The amount of insoluble fraction was calculated as the difference of the sample weight before and after extraction.

\subsection{Kinetics of Photocross-Linking}

The investigation of photocross-linking kinetics was carried out as repored earlier [10].

\subsection{Thermal Analysis}


Glass transition temperature ( $\mathrm{Tg}$ ) of the photocross-linked polymers was estimated by differential scanning calorimetry (DSC). The measurements were performed on a Perkin Elmer DSC 8500 apparatus with heating-cooling-heating rate of $10^{\circ} \mathrm{C} \cdot \mathrm{min}^{-1}$ under nitrogen atmosphere (nitrogen flow rate $\left.50 \mathrm{~mL} \cdot \mathrm{min}^{-1}\right)$. The Tg value was taken as the middle point in the heat capacity step of the glass transition.

Thermogravimetric analysis (TGA) measurements of prepared polymers were performed on a Perkin Elmer TGA 4000 apparatus in the temperature range from room temperature to $800{ }^{\circ} \mathrm{C}$ at a heating rate of $20^{\circ} \mathrm{C} \cdot \mathrm{min}^{-1}$ under nitrogen atmosphere (nitrogen flow rate $100 \mathrm{ml} \cdot \mathrm{min}^{-1}$ ).

\subsection{Mechanical Testing}

Mechanical properties of the photocross-linked polymer tablets were estimated by compression test on a BDO-FB0.5TH (Zwick/Roell) testing machine as reported earlier [10].

\section{Results}

\subsection{Real-Time Photorheometry}

In this study, AESO was used as the main component which is easily UV/VIS-curable biobased material. Synthetic cross-linking agent DVB was used to improve mechanical properties of polymer. As an alternative for DVB, the plant-derived bifunctional VDM was used. MYR was used to control mixture viscosity and dissolve solid components. The images of photocross-linked polymer tablets are presented in Figure 2. Due to three double bonds, MYR acts as a reactive diluent, which connects into polymer network [11]. 3 mol. \% of DMPA was used to initiate the photopolymerization of biobased resins.

Table 1. Compositions of photo-resins.

\begin{tabular}{ccc}
\hline Resin & MRM1, AESO:MYR: Aromatic Compound & Used Aromatic Compound \\
\hline S1 & $1: 1: 1$ & DVB \\
S2 & $1: 3: 1$ & DVB \\
S3 & $1: 5: 1$ & DVB \\
S4 & $1: 1: 1$ & VDM \\
S5 & $1: 3: 1$ & VDM \\
S6 & $1: 5: 1$ & VDM \\
S7 & $1: 1: 3$ & DVB \\
S8 & $1: 1: 5$ & DVB \\
S9 & $1: 1: 3$ & VDM \\
S10 & $1: 1: 5$ & VDM \\
\hline
\end{tabular}




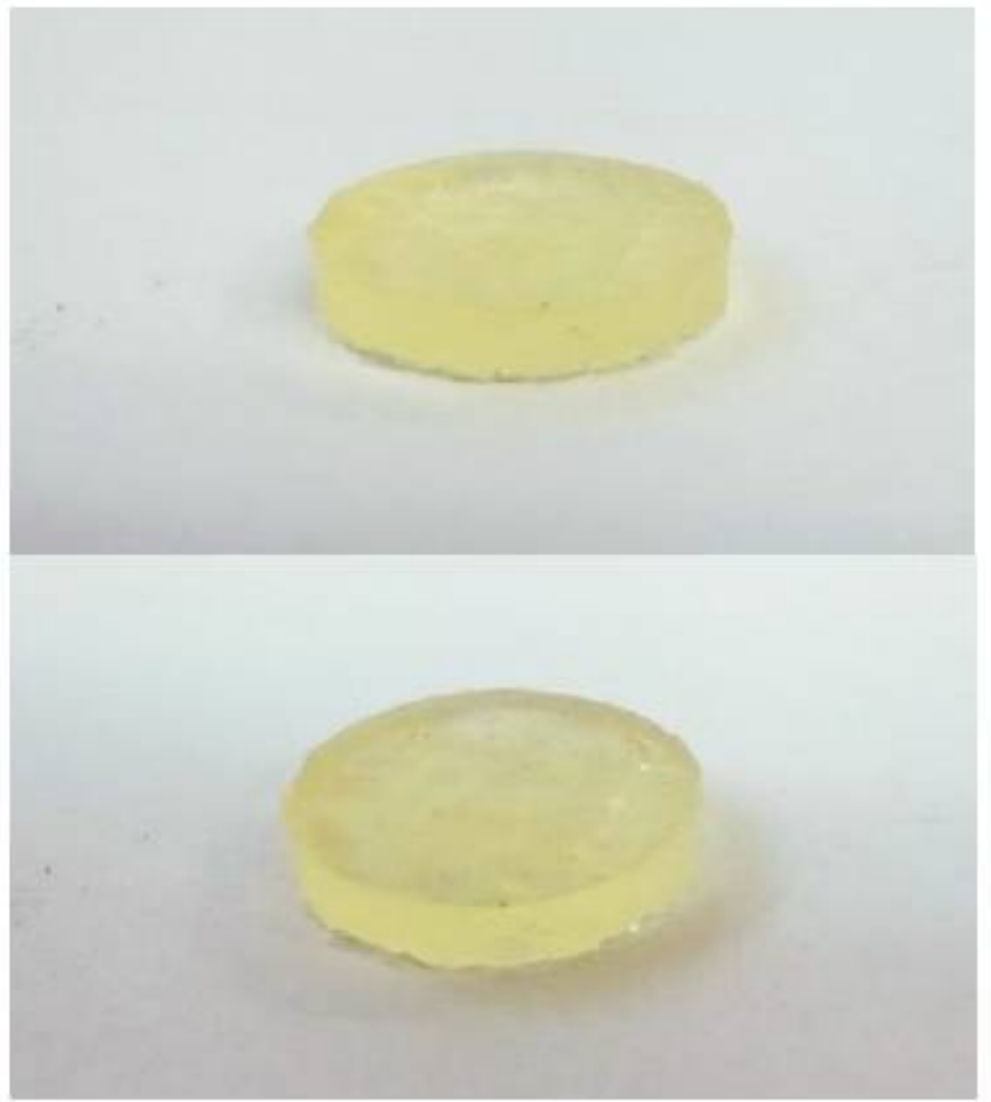

Figure 2. Photocross-linked polymer tablets of S2 (top) and S4 (bottom) (a); Compositions of photoresins $(\mathbf{b})$.

Ten different designed resins (S1-S10 Table 1) were investigated to determine the influence of their composition to the reaction rate and properties of the resulting polymers. The kinetics of photocross-linking of resins S1-S10 was monitored by the real-time photorheometry. Storage modulus $\mathrm{G}^{\prime}$ and gel time (tgel) were measured. Time dependencies of storage modulus $\mathrm{G}^{\prime}$ of the resins are shown in Figure 2.

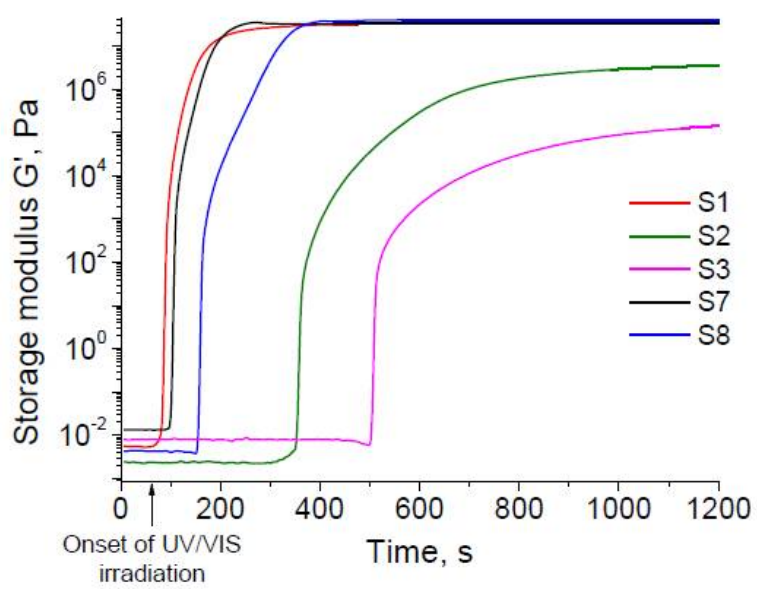

(a)

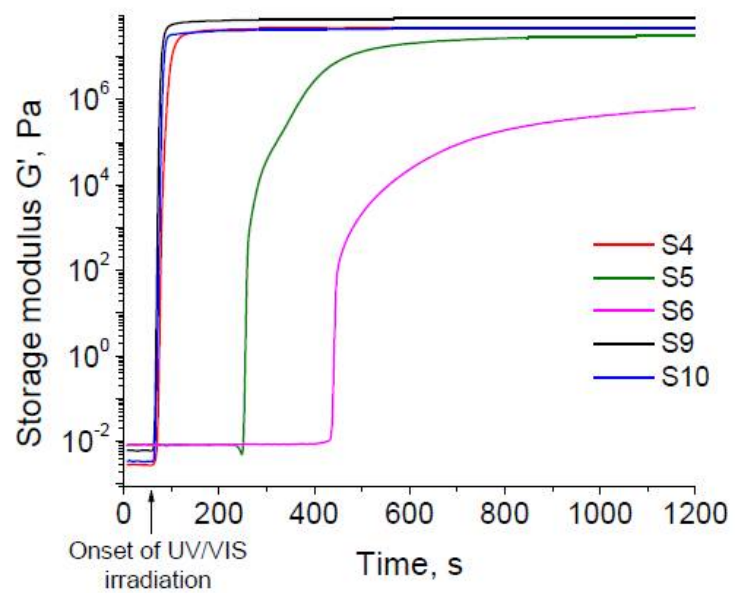

(b)

Figure 2. Time dependencies of storage modulus $G^{\prime}$ of the resins with different aromatic compounds: $\operatorname{DVB}(\mathbf{a})$ and $\operatorname{VDM}(\mathbf{b})$.

It was observed, that resins with higher amount of MYR showed significantly lower values of $\mathrm{G}^{\prime}$ and highly increased tgel (Figure 3a). A slow formation of soft and rubbery polymer confirmed 
the widespread MYR usage in small amounts as comonomer to adjust elastomeric properties as a soft block [12]. Comparing resins with higher amount of MYR and different aromatic compounds, resins S1-S3 containing plant-derived VDM showed the higher photocross-linking rate than those containing petroleum-derived DVB (S4-S6). Moreover, the resins with VDM showed the higher $\mathrm{G}^{\prime}$ values than those with DVB corresponding to better mechanical properties of the first polymers.

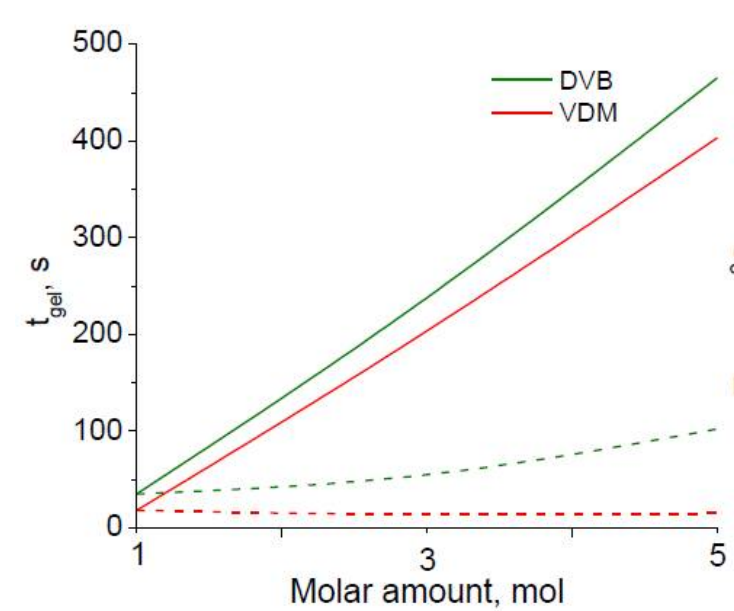

(a)

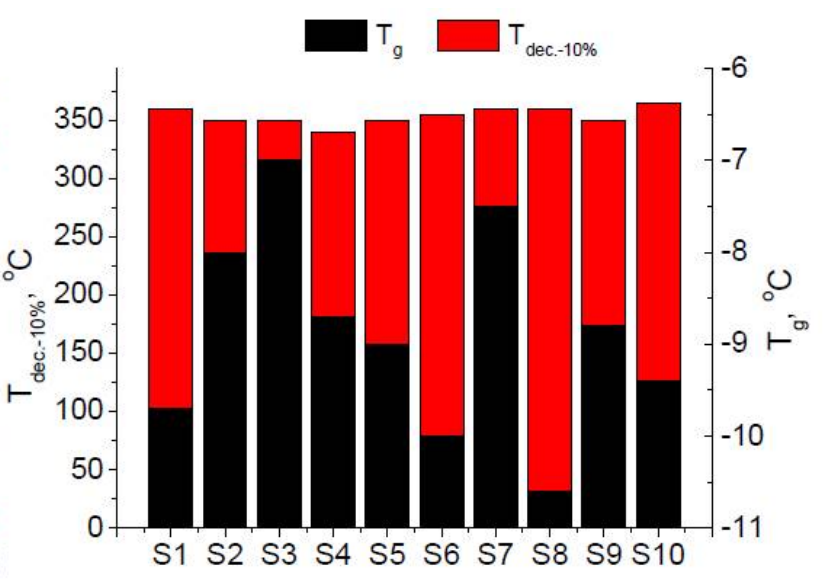

(b)

Figure 3. The dependency of the gel time (tgel) of the resins with different amounts of MYR (solid) and aromatic compound (dashed) (a); Thermal properties of cross-linked polymers (b).

Resins with higher amount of aromatic compound showed higher maximum values of $\mathrm{G}^{\prime}$ indicating the formation of more rigid cross-linked network. It was observed that resins with higher amount of DVB indicated extensively prolonged gel time, though higher values of $G^{\prime}$ were monitored as well. This confirmed the DVB effectiveness as comonomer improving mechanical properties of the polymer [13], despite the long induction period.

It was determined, that VDM was more efficient aromatic compound comparing to DVB, due to the improved tgel and higher $G^{\prime}$ values. Short gel time of the resins with VDM indicated high photosensitivity of the compound, which is one of the most important features for optical 3D printing [14]. The resin with $3 \mathrm{~mol} \%$ of VDM (S9) showed the shortest tgel (12 s) and the highest values of $\mathrm{G}^{\prime}$ (7.78.107 Pa).

\subsection{Characterization of Photocross-Linked Polymer Structure}

Formed cross-linked polymer structure was confirmed by Soxhlet extraction. The yields of insoluble fraction (YIF) of the cross-linked polymers were in the range of (53-99)\% (Figure 4). It was observed that polymers with higher amount of MYR caused lower YIF values of the cross-linked polymer confirming the formation of MYR linear and/or branched polymer chains [15]. The higher YIF values of the photocross-linked polymers with VDM fragments were observed compared to those with DVB fragments. This could be explained by the acrylate ability exhibit high reaction rate and high values of YIF [16]. However, no significant influence of the amount of aromatic component to the yield of insoluble fraction of the synthesized polymers was observed.

\subsection{Thermal Properties}

DSC confirmed that all synthesized photocross-linked polymers were amorphous materials. The values of the glass transition temperatures $(\mathrm{Tg})$ of biobased polymers varied in the range of $(-10.6-$ $-7)^{\circ} \mathrm{C}$. (Figure $3 b$ ), which were caused by the flexible chains of AESO and MYR. Due to the crosslinked structure, the solid state of synthesized polymers at room temperature was observed. TGA confirmed that the photocross-linked polymers exhibited high thermal stability. The $10 \%$ weight loss 
temperatures (Tdec-10\%) of all photocross-linked polymers were in the close range and varied from $340{ }^{\circ} \mathrm{C}$ to $365^{\circ} \mathrm{C}$ (Figure $3 b$ ).

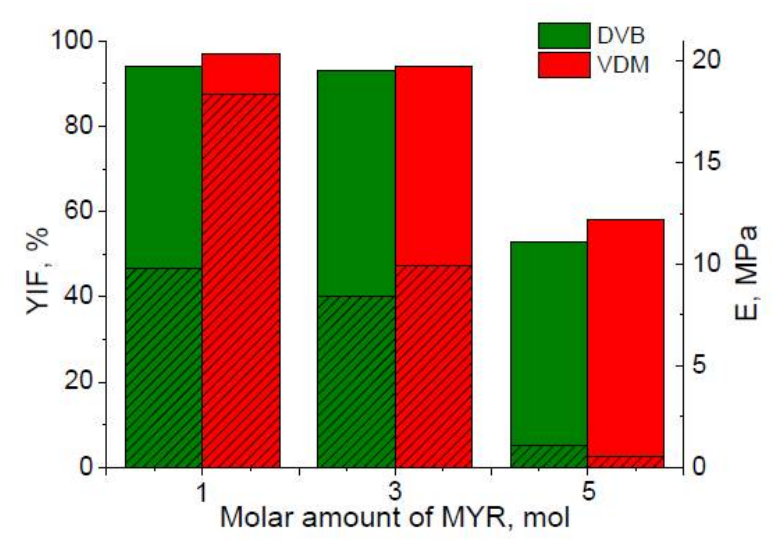

(a)

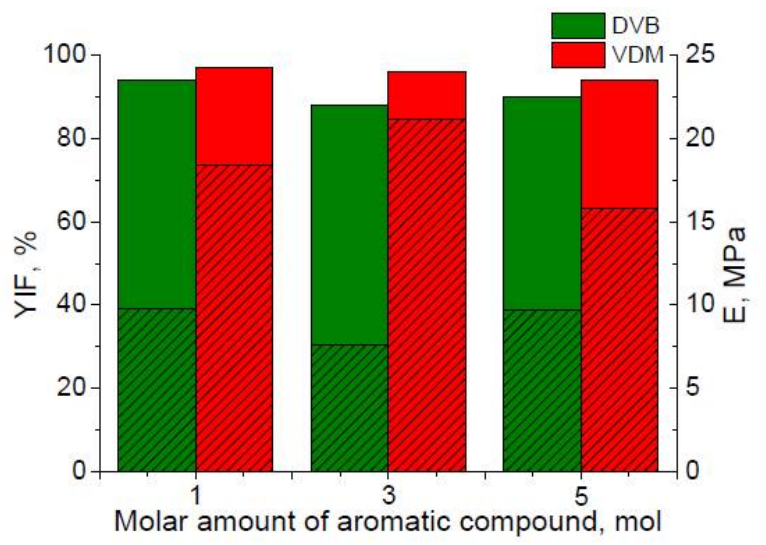

(b)

Figure 4. The dependency of the Young's modulus (E) (striped) and yield of insoluble fraction (YIF) (solid) of the polymers with different amounts of MYR (a) and aromatic compound (b).

\subsection{Mechanical Properties}

The mechanical properties of the synthesized cross-linked polymer samples were investigated by the top pressure test. It was determined that the value of the Young's modulus decreased when the higher amount of MYR was added to the resin (Figure 4). This significant reduction of E was caused by the formation of soft and flexible MYR chains followed by the formation of the lower amount of cross-links and leading to the loss of polymer stiffness [17]. It was observed that the higher value of the Young's modulus was reached when the higher yield of insoluble fraction was determined. Photocross-linked polymers with VDM fragments showed the higher values of the Young's modulus compared to the polymers with DVB fragments, what could be due to the higher values of YIF.

\section{Conclusions}

The novel cross-linked polymers were synthesized from acrylated epoxidized soybean oil, myrcene and divinylbenzene or vanillin dimethacrylate by UV/VIS photopolymerization. It was determined that photopolymerization rate and properties of the cross-linked polymers were highly depended on the resin composition. It was observed that even though myrcene reduced the resin viscosity, it also significantly prolonged the photocross linking reaction, and impaired mechanical properties of synthesized polymers. The replacement of petroleum-derived aromatic component divinylbenzene by plant-derived vanillin dimethacrylate led to the faster photocross linking reaction, improved mechanical and thermal properties of polymers. The resin composed of only plant-derived monomers, acrylated epoxidized soybean oil, myrcene, and vanillin dimethacrylate, molar ratio 1:1:3, showed the most favorable properties and was selected as a potential renewable photoresin for application in optical 3D printing.

Author Contributions: J.O. and M.L. conceived and designed the experiments, analyzed the data; M.L. performed all experiments and characterizations. All of the Authors contributed to writing the manuscript.

Acknowledgments: Financial support from the EU ERDF, through the INTERREG BSR Programme (ECOLABNET project No. \#R077), is gratefully acknowledged.

Conflicts of Interest: The authors declare no conflicts of interest. 


\section{References}

1. Juskova, P.; Ollitrault, A.; Serra, M.; Viovy, J.; Malaquin, L. Resolution Improvement of 3D StereoLithography through the Direct Laser Trajectory Programming: Application to Microfluidic Deterministic Lateral Displacement Device. Anal. Chim. Acta 2018, 1000, 239-247.

2. Patil, D.M.; Phalak, G.A.; Mhaske, S. Design and Synthesis of Bio-Based UV Curable PU Acrylate Resin from Itaconic Acid for Coating Applications. Des. Monomers Polym. 2017, 20, 269-282.

3. Kim, H.; Kim, H.; Kim, B.S. Soybean Oil-Based Photo-Crosslinked Polymer Networks. J. Polym. Environ. 2010, 18, 291-297.

4. Ferreira, G.R.; Braquehais, J.R.; da Silva, W.N.; Machado, F. Synthesis of Soybean Oil-Based Polymer Lattices Via Emulsion Polymerization Process. Ind. Crops Prod. 2015, 65, 14-20.

5. Liu, K.; Madbouly, S.A.; Kessler, M.R. Biorenewable Thermosetting Copolymer Based on Soybean Oil and Eugenol. Eur. Polym. J. 2015, 69, 16-28.

6. Fache, M.; Boutevin, B.; Caillol, S. Vanillin Production from Lignin and its use as a Renewable Chemical. ACS Sustain. Chem. Eng. 2015, 4, 35-46.

7. Allnex Belgium SA. Ebecryl 860 Technical Data Sheet. Available online: https://www.palmerholland. com/Assets/User/Documents/Product/40754/4912/MITM00452.pdf (accessed on).

8. Zheng, H.; Li, C.; Chen, J.; Chen, J.; Zhao, S.; Wang, Y. Mechanism and Kinetics of the Pyrolysis of B-Pinene to Myrcene. J. Anal. Appl. Pyrolysis 2016.

9. Behr, A.; Johnen, L. Myrcene as a Natural Base Chemical in Sustainable Chemistry: A Critical Review. ChemSusChem 2009, 2, 1072-1095.

10. Lebedevaite, M.; Ostrauskaite, J.; Skliutas, E.; Malinauskas, M. Photoinitiator Free Resins Composed of Plant-Derived Monomers for the Optical M-3D Printing of Thermosets. Polymers 2019, 11, 116.

11. Tomeckova, V.; Norton, S.J.; Love, B.J.; Halloran, J.W. Photopolymerization of Acrylate Suspensions with Visible Dyes. J. Eur. Ceram. Soc. 2013, 33, 699-707.

12. Zhou, C.; Wei, Z.; Jin, C.; Wang, Y.; Yu, Y.; Leng, X.; Li, Y. Fully Biobased Thermoplastic Elastomers: Synthesis of Highly Branched Linear Comb Poly (B-Myrcene)-Graft-Poly (L-Lactide) Copolymers with Tunable Mechanical Properties. Polymer 2018, 138, 57-64.

13. Ronda, J.C.; Lligadas, G.; Galià, M.; Cádiz, V. A Renewable Approach to Thermosetting Resins. React. Funct. Polym. 2013, 73, 381-395.

14. Skliutas, E.; Kašetaite, S.; Jonusauskas, L.; Ostrauskaite, J.; Malinauskas, M. Renewable Materials as 3D Photostructurable Resins Employing 405 Nm Tabletop Dynamic Projection Lithography (Conference Presentation). In Advanced Fabrication Technologies for Micro/Nano Optics and Photonics XI; p. 105440R.

15. Liu, B.; Li, L.; Sun, G.; Liu, D.; Li, S.; Cui, D. Isoselective 3, 4-(Co) Polymerization of Bio-Renewable Myrcene using NSN-Ligated Rare-Earth Metal Precursor: An Approach to a New Elastomer. Chem. Commun. 2015, 51, 1039-1041.

16. Ge, X.; Ye, Q.; Song, L.; Misra, A.; Spencer, P. Visible-Light Initiated Free-Radical/Cationic Ring-Opening Hybrid Photopolymerization of Methacrylate/Epoxy: Polymerization Kinetics, Crosslinking Structure, and Dynamic Mechanical Properties. Macromol. Chem. Phys. 2015, 216, 856-872.

17. Zhang, J.; Schneiderman, D.K.; Li, T.; Hillmyer, M.A.; Bates, F.S. Design of Graft Block Polymer Thermoplastics. Macromolecules 2016, 49, 9108-9118.

Publisher's Note: MDPI stays neutral with regard to jurisdictional claims in published maps and institutional affiliations.

(C) 2020 by the authors. Submitted for possible open access publication under the terms and conditions of the Creative Commons Attribution (CC BY) license (http://creativecommons.org/licenses/by/4.0/). 